\section{Компьютерное моделирование работы лесокультурных агрегатов}

\author{
А. В. Родионов ${ }^{1}$ \\ Петрозаводский государственный университет
}

\section{АННОТАЦИЯ}

В статье описывается новая программа ЭВМ, предназначенная для моделирования работы лесокультурных агрегатов и расчета параметров механизированных работ по лесовосстановлению.

Ключевые слова: лесовосстановление, механизация, компьютерное моделирование.

\section{SUMMARY}

The new program for the computer-aided modeling of mechanized artificial reforestation processes and calculating of their basic parameters is described in the article.

Keywords: artificial reforestation, mechanization, computer-aided modeling.

Актуальной проблемой практического применения технологии комплексного освоения лесной площади (КОЛП) является прогнозирование возможности применения конкретного типа лесокультурного агрегата в условиях нераскорчеванной вырубки и обоснование рациональной схемы движения агрегата по площади [1].

В Петрозаводском государственном университете (ПетрГУ) разработана методика моделирования работы лесокультурных агрегатов на нераскорчеванных вырубках, позволяющая обосновать рациональную схему движения этих агрегатов по пасекам путем представления вырубки как среды случайных препятствий [2].

С целью автоматизации процесса моделирования работы лесокультурных агрегатов по методике [2] в ПетрГУ разработана программа «Анализ траектории движения машины по плану вырубки», предназначенная для эксплуатации на персональных электронно-вычислительных машинах (ПЭВМ) типа IBM РС и совместимых с ними в среде MS DOS и Windows [3].

Программа позволяет в интерактивном режиме (т. е. при непосредственном участии оператора ПЭВМ) моделировать движение лесокультурного агрегата и производить расчеты, связанные с планированием механизированных работ по лесовосстановлению согласно вышеупомянутой методике. Программа является дальнейшим развитием разработанной ранее программы для ЭВМ «Исследование вырубки» [3].

\footnotetext{
${ }^{1}$ Автор - докторант кафедры технологии и оборудования лесного комплекса

(C) А. В. Родионов, 2003
}

После запуска загрузочного модуля (исполняемого файла glade.exe) на экране появляется заставка программы (рис. 1). Нажатие на любую клавишу позволяет перейти в главное окно программы (рис. 2).

В верхней части главного окна находится горизонтальное меню (см. рис. 2). Здесь следует, пользуясь клавишами управления курсором, выбрать один из разделов программы: «Загрузить»; «Создать»; «Изменить»; «Сохранить»; «Выполнить»; «Выход». Для этого необходимо установить световую полосу на один из разделов программы и нажать ENTER. После нажатия на клавишу ENTER управление передается в выбранный раздел программы.

В разделе «Загрузить» можно загрузить в память программы для обработки одну из ведомостей встречаемости препятствий на поверхности вырубки, сохраненную ранее в файле с расширением GLD.

После выбора раздела «Создать» и нажатия на клавишу ENTER происходит очистка памяти и управление передается в раздел «Изменить» для ввода новой ведомости встречаемости препятствий.

Раздел «Изменить» предназначен для редактирования ранее созданных ведомостей или создания новых.

Раздел «Сохранить» предназначен для сохранения вновь созданных или отредактированных ведомостей в файл с расширением GLD на жестком диске.

Раздел «Выполнить» предназначен для обработки ведомостей встречаемости препятствий на поверхности вырубки. Перед началом работы с данным разделом необходимо обязательно загрузить в память программы какую-либо ведомость препятствий.

После выбора раздела «Выполнить» и нажатия на клавишу ENTER на экране появится окно, в котором предлагается на выбор: загрузить в память программы уже построенную траекторию или построить новую. Выбор дальнейшего варианта действий осуществляется с помощью клавиш управления курсором и клавиши ENTER.

В случае выбора строки «Загрузить траекторию» на экране появится окно «Выбор файла», в котором можно загрузить для просмотра в полноэкранном режиме (рис. 3) одну из ранее созданных траекторий движения лесокультурного агрегата, сохраненную в файле с расширением TRK.

В случае выбора строки «Построить траекторию» в полноэкранном режиме появится изображение ленты, заключенное между двумя линиями (рис. 4). Если в память программы уже загружена какая-либо ведомость, то на ленту будут нанесены условные обозначения всех представленных в ведомости препятствий. На экране также отображается условный контур лесокультурного агрегата. Внутри контура выводится расстояние от левого края ленты до продольной оси агрегата. 


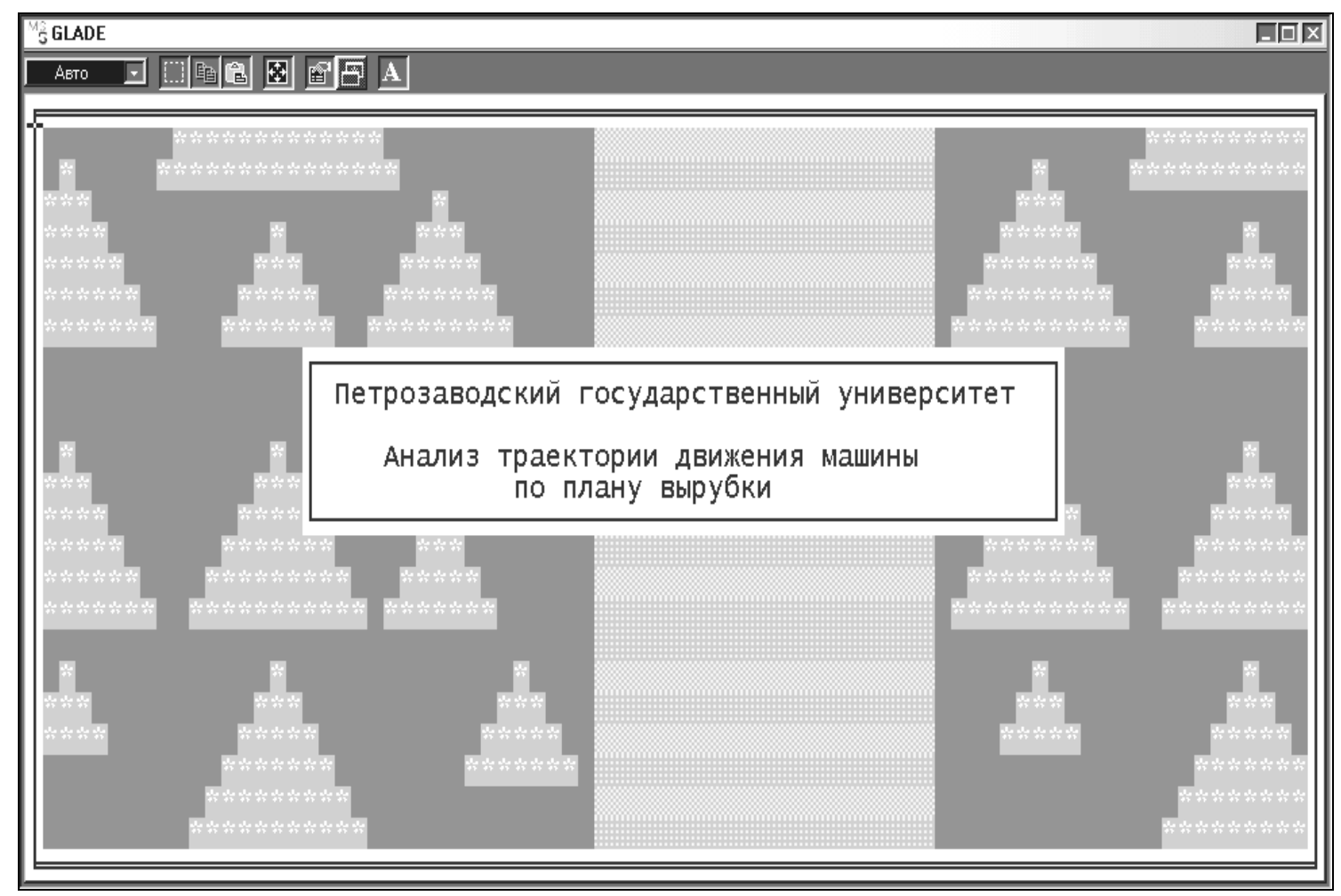

Рис. 1. Заставка программы

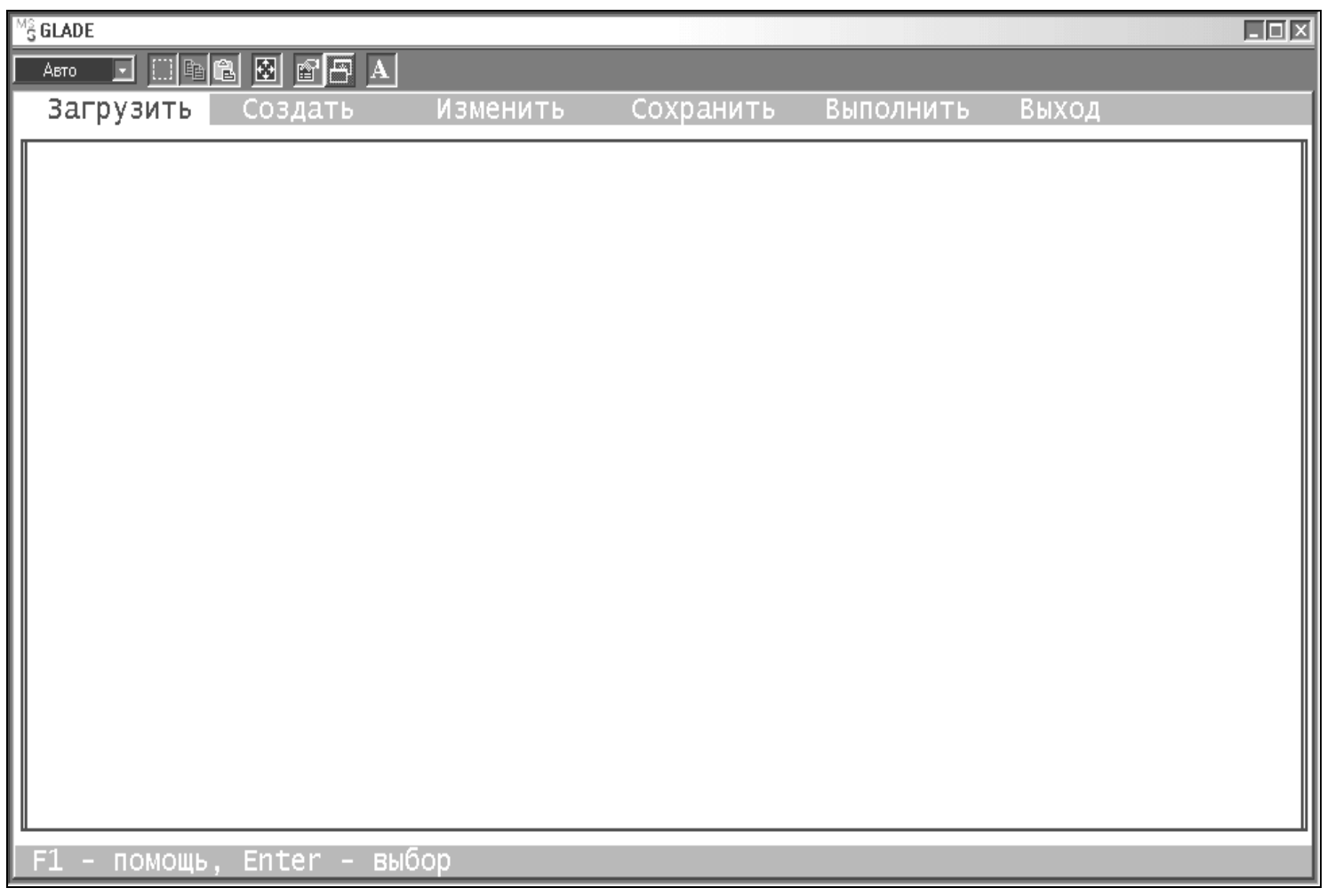

Рис. 2. Главное окно программы 


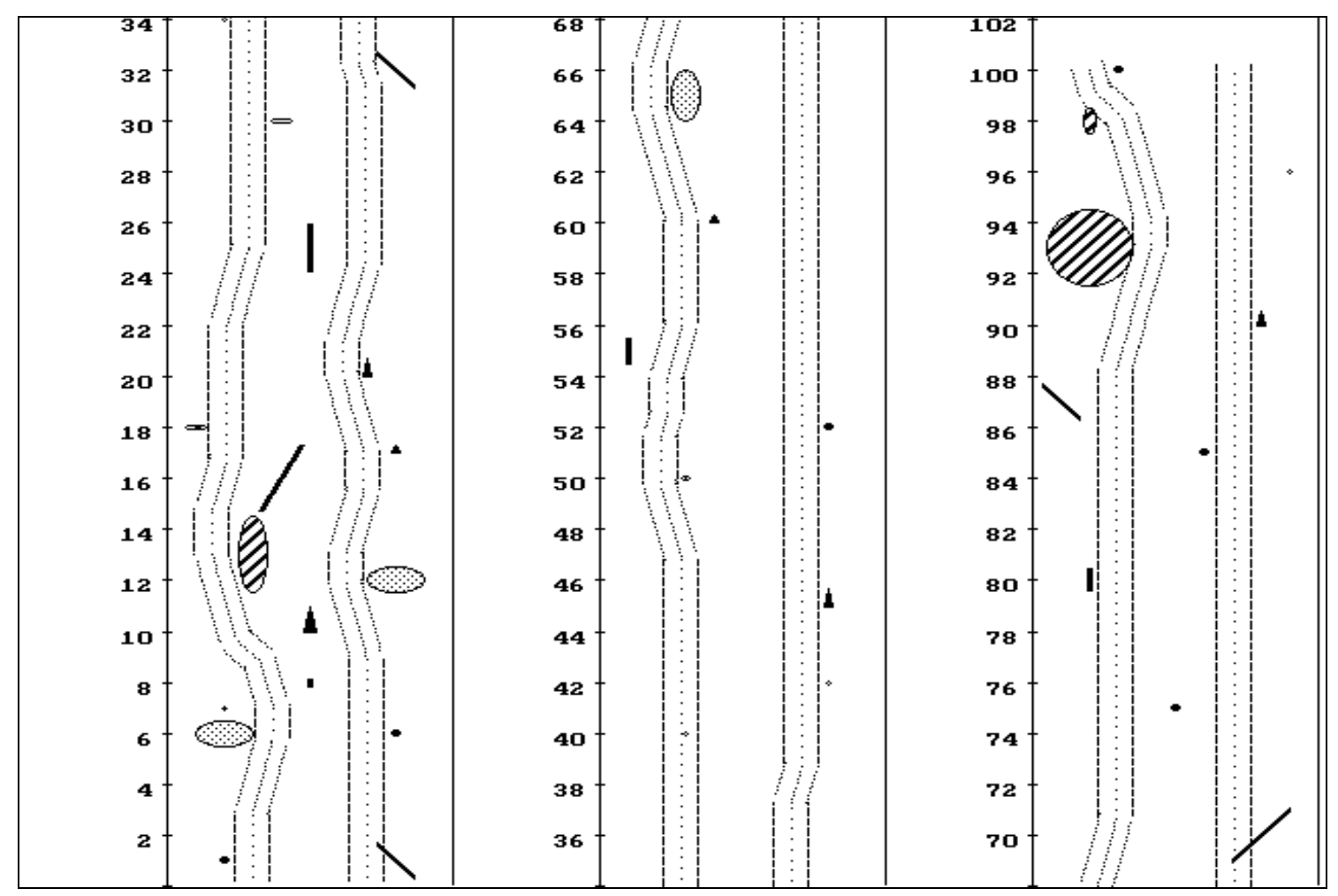

Рис. 3. Траектория движения лесокультурного агрегата

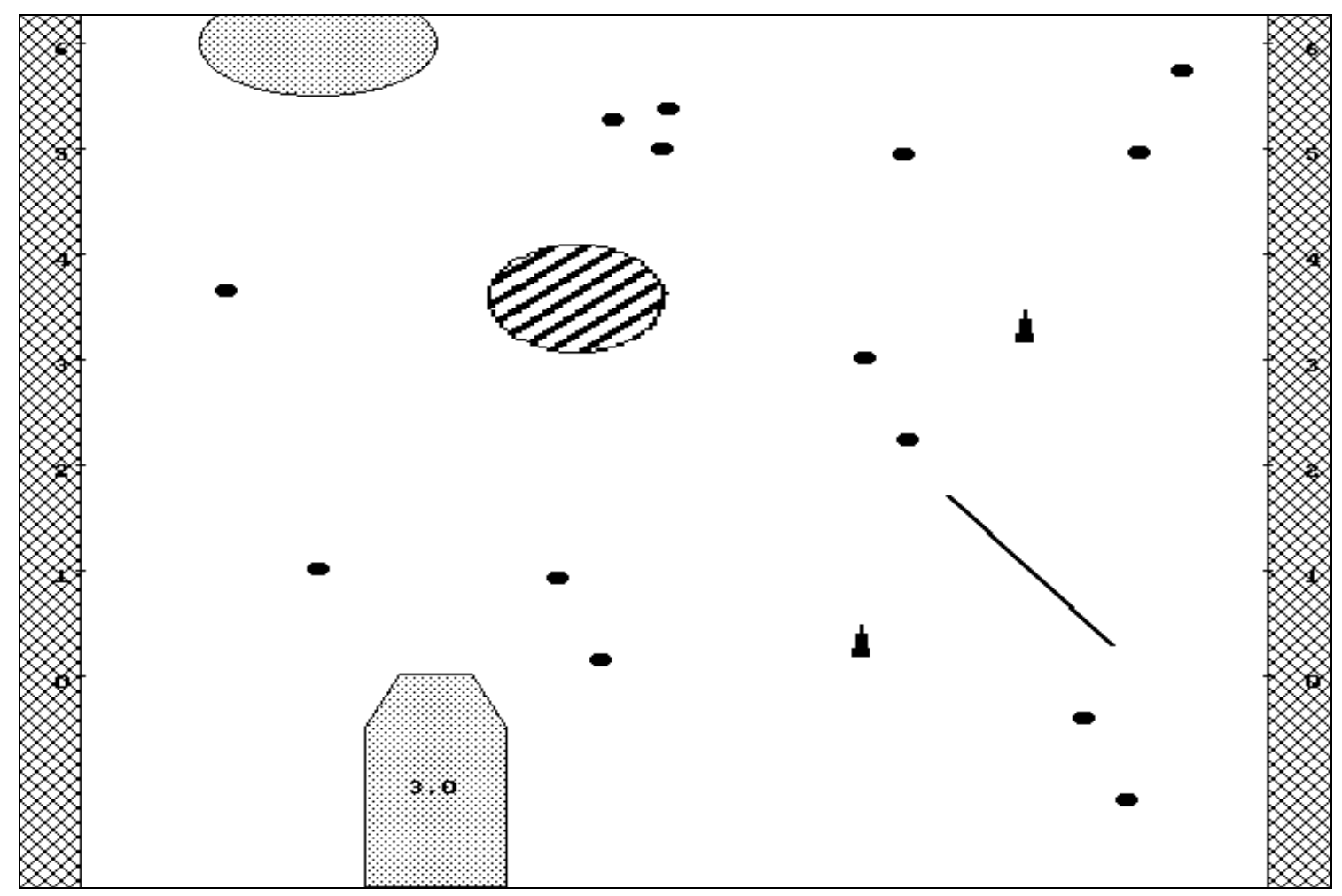

Рис. 4. Построение траектории движения лесокультурного агрегата 
В исходном положении агрегат находится на расстоянии 3 м от левого края ленты. Для интерактивного управления движением агрегата по ленте используются клавиши курсора.

Согласно методике [2], первый проход агрегата по ленте следует производить, соблюдая расстояние 3 м от левого края ленты. Второй проход агрегата по ленте следует производить, соблюдая расстояние 7 м от левого края ленты. Для удобства оператора величина расстояния от левого края ленты отображается внутри контура агрегата (см. рис. 4).

После осуществления двух проходов по ленте на экране появляется план всей ленты с нанесенной на нее траекторией движения агрегата (см. рис. 3).

После успешного сохранения вновь созданной траектории в файл с расширением TRK на жестком диске на экран выводится информация о расстояниях между трассами на ленте в виде гистограммы (рис. 5).

После нажатия на клавишу F3 на экран выводятся результаты моделирования (рис. 6), необходимые для расчета технологических процессов механизированных лесовосстановительных работ по методике [2]:

- «Длина трассы» - фактическое расстояние в метрах, пройденное лесокультурным агрегатом при каждом проходе и всего по ленте;

- «Дефект трассы» - фактическая суммарная длина дефектных участков в метрах при каждом проходе и всего по ленте;

- «К2» - вероятность выполнения задания лесокультурным агрегатом по параметру встречаемости препятствий на поверхности вырубки - по каждому проходу и суммарно по ленте;

- «К3» - коэффициент удлинения рабочего хода агрегата на поверхности вырубки - по каждому проходу и суммарно по ленте;

- «Пройдено препятствий» - количество препятствий, преодоленных лесокультурным агрегатом, - по каждому проходу и суммарно по ленте;

- «Ср. полож. на трассе» - фактическая ось движения лесокультурного агрегата в метрах, т. е. расстояние от левого края ленты до продольной оси агрегата, - раздельно по каждому проходу;

- «Сред. квадр. откл.» - среднее квадратическое отклонение от заданной оси движения лесокультурного агрегата в метрах квадратных - раздельно по каждому проходу.

Для выхода из раздела «Выполнить» в главное окно необходимо нажать клавишу F10. При этом программа предлагает сохранить параметры вновь построенной траектории движения лесокультурного агрегата и сведения о препятствиях на ленте в файл с расширением TXТ на жестком диске.

После выбора клавишами управления курсором в главном окне программы раздела «Выход» и нажатия на клавишу ENTER происходит прекращение работы программы с потерей всех несохраненных данных.
Подробнее с возможностями программы «Анализ траектории движения машины по плану вырубки» можно ознакомиться, прочитав инструкцию [3] или же краткую информацию непосредственно из программы, нажав клавишу F1.

Описанная программа внедрена и используется на лесоинженерном факультете ПетрГУ при выполнении расчетных работ, курсового и дипломного проектирования по дисциплинам: «Технология и машины лесовосстановления» специальности 260100 «Лесоинженерное дело», «Машины и механизмы» специальности 260400 «Лесное хозяйство», «Технология и оборудование лесопромышленных предприятий: Технология и оборудование лесовосстановления» специальности 170400 «Машины и оборудование лесного комплекса».

В настоящий момент осуществляется разработка пакета программ для ПЭВМ типа IBM РС и совместимых с ними по моделированию работы динамических лункообразователей типа Л-2 и Л-2У. В пакет планируется включить базу данных по распределению случайных препятствий на поверхности вырубок в различных типах леса, работающую на ее основе программу для оптимизации движения лесокультурного агрегата по поверхности вырубки, а также программу, позволяющую моделировать движение лесокультурного агрегата в интерактивном режиме.

Пакет программ также основывается на методике [2], что позволит с максимальной точностью смоделировать работу динамических лункообразователей, спрогнозировать возможность их применения в условиях нераскорчеванных вырубок в различных типах леса и создать предпосылки для дальнейшего совершенствования конструкции лункообразователей с целью повышения надежности их работы в условиях естественной лесной среды.

\section{СПИСОК ЛИТЕРАТУРЫ}

1. Родионов А. В. Обоснование технологического процесса комплексного освоения лесных площадей на основе ресурсосбережения: Дис...канд. техн. наук. Петрозаводск: Изд-во ПетрГУ, 2000. $185 \mathrm{c}$.

2. Цыпук А. М. Моделирование процессов работы лесокультурных агрегатов на нераскорчеванных вырубках: Учеб. пособие. Петрозаводск: Изд-во ПетрГУ, 1997. 44 с.

3. Родионов А. В. Инструкция по эксплуатации программы для ЭВМ «Анализ траектории движения машины по плану вырубки» / А. В. Родионов, Е. К. Белый; Петрозав. гос. ун-т. Петрозаводск, 2002. 24 с.: ил. Деп. в ВИНИТИ 29.07.2002, № 1422-B2002. 


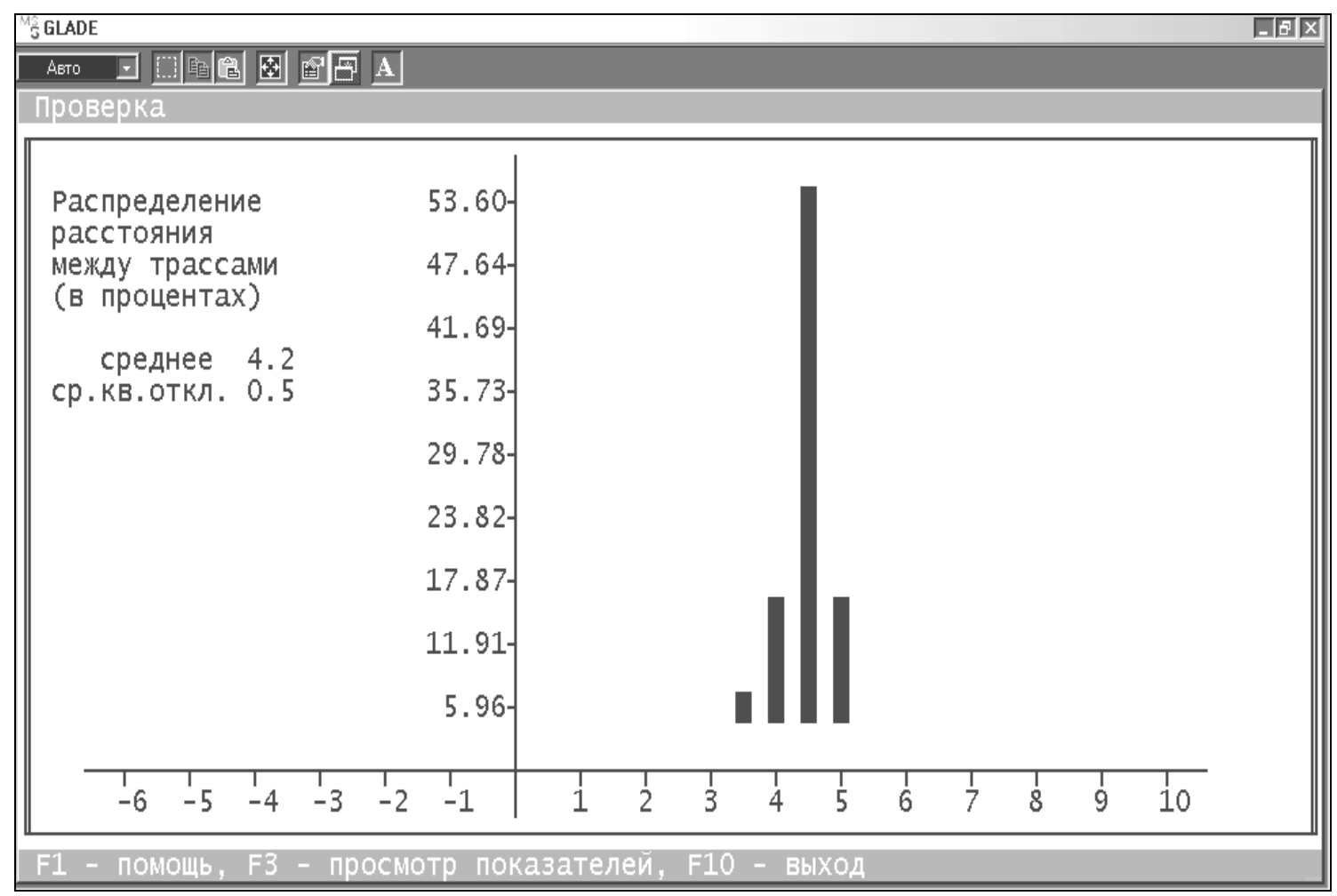

Рис. 5. Вывод информации о расстояниях между трассами

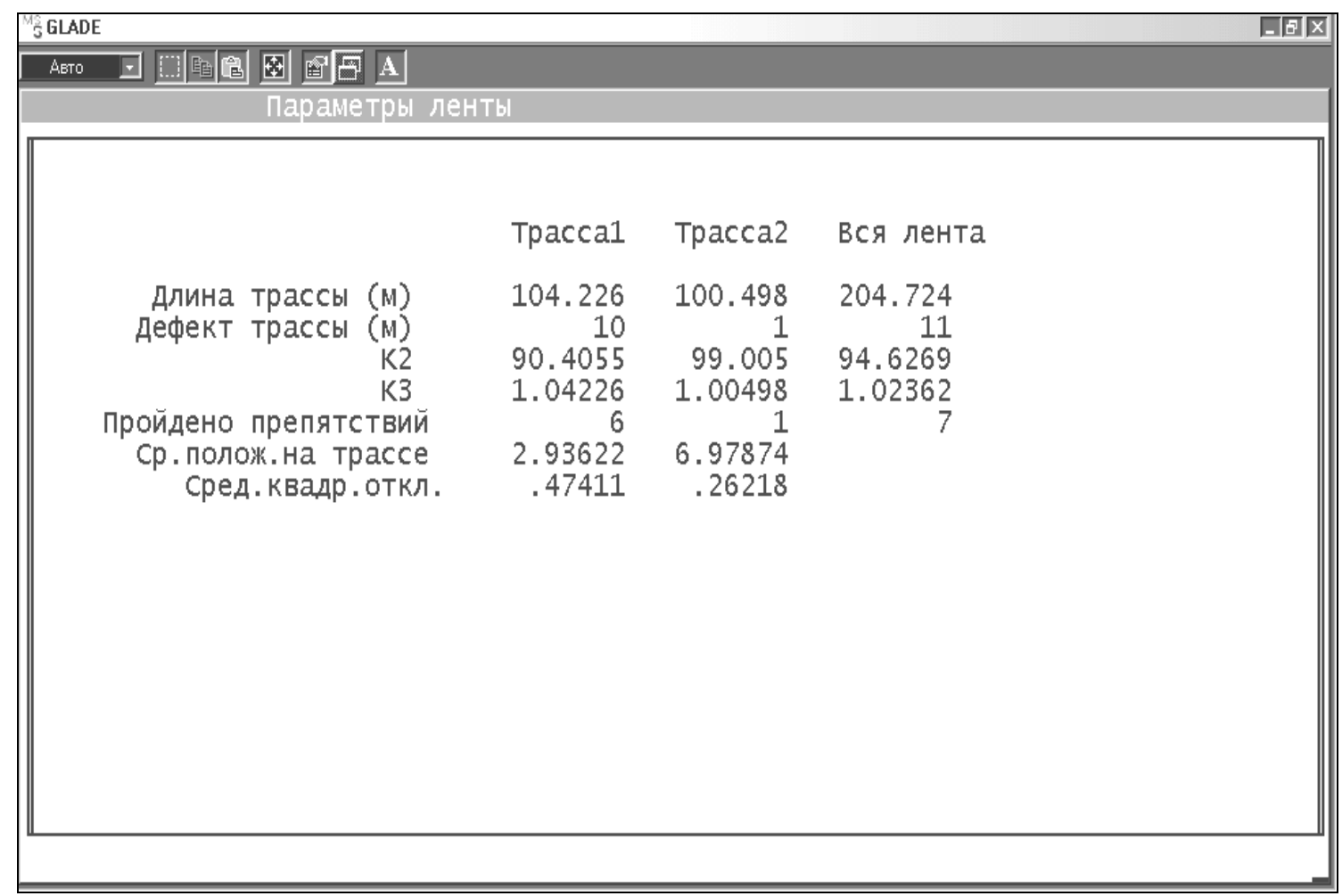

Рис. 6. Вывод параметров смоделированной траектории 